\title{
International representation in psychiatric
}

\section{literature}

\author{
Survey of six leading journals ${ }^{\dagger}$
}

VIKRAM PATEL and ATHULA SUMATHIPALA

\begin{abstract}
Background Despite the growing recognition of the global burden of psychiatric disease, there are questions about the strength of the evidence base from non-Western societies.
\end{abstract}

\section{Aims To compare the contribution of Euro-American countries and the rest of the world (RoW) to psychiatric literature. \\ Method Survey of the country of origin of papers submitted to and published in six leading psychiatric journals over a 3-year period (1996-1998).}

\section{Results Only $6 \%$ of the literature is} published from regions of the world that account for over $90 \%$ of global population. The three journals published in Europe had a significantly higher proportion of international articles when compared to the three American journals. Less than 1\% of all published articles described mental health interventions in the RoW.

Acceptance rates were significantly lower for papers submitted from the RoW.

Conclusions There is a gross underrepresentation of research from the RoW. This has implications for the development of a truly international psychiatry.

Declaration of interest None.
The past decade has witnessed a spectacular rise in the profile of mental disorders in the global public health debate. Several influential reports have brought together data demonstrating that mental disorders are common and disabling (e.g. Murray \& Lopez, 1996). These reports have underlined the need for evidence to influence health policy and practice for mental health, focusing on developing countries where there is the greatest unmet need. The evidence which influences policy is often derived from research published in leading journals. The need for psychiatric research to reflect the diverse realities of the health systems and cultural factors is crucial if research is to inform local health policy and practice (Patel, 2000a). Thus, articles derived from studies of health systems in developed countries are likely to be of less relevance to mental health professionals in developing countries. Furthermore, psychiatrists and policy-makers in many developing countries have limited access to international journals because medical libraries often need to make a choice from a number of high-impact journals owing to financial constraints. Thus, the proportion of international representation in psychiatric journals may be a crucial factor in influencing the choice of journals in developing countries.

The study described in this paper had two aims: first, to determine the overall contribution of different regions of the world to the psychiatric literature published in high-impact journals; and second, to identify which high-impact journals provide an international representation in their contents and would thus be an appropriate choice for psychiatrists in the international context. We chose to determine, in a range of high-impact psychiatric journals, the proportion of articles which include authorship or data from scientists based in any country outside Western Europe, North America and Australia/New Zealand (termed 'Euro-American' countries). This distinction was drawn in recognition of the fact that the Euro-American countries shared many cultural and economic features and were all economically and culturally linked. The rest of the world (RoW) group included Eastern Europe, which although culturally related to Western Europe was not economically on the same level, and Japan, which was highly developed economically but did not share many cultural factors with Euro-American countries. Other objectives were to describe the relative contribution of various regions in the RoW and the type of research articles, focusing on the specific issue of intervention research.

\section{METHOD}

A retrospective review of all issues in 1996, 1997 and 1998 was conducted of the following journals: British Journal of Psychiatry, American Journal of Psychiatry, Acta Psychiatrica Scandinavica, Psychological Medicine, Archives of General Psychiatry and Schizophrenia Bulletin.

The rationale for selection of these journals was that these were all high-impact psychiatric journals. Three journals were published in Western Europe and three in North America. All articles, excluding Correspondence, Book Reviews and News articles, were reviewed. Articles which included either data or authorship from the RoW were identified and data on the country of origin was recorded. A content analysis of the articles was carried out to estimate the proportion of articles describing interventions for psychiatric disorders. The editorial offices of all six journals were approached to determine the numbers of papers submitted from various regions or countries and to examine whether there was any acceptance bias.

\section{RESULTS}

In total, 2902 articles were published in these six journals over the 3-year review period. The total number of articles from the RoW was $173(6 \%)$. The proportion of RoW articles in each journal is shown in Table 1. The distribution of the proportional contribution of specific regions of the RoW is shown in Figure 1. The distribution of which journals are the most popular for different regions of the RoW is shown in Table 2. The table also shows 
Table I The proportion of articles from the rest of the world (RoW) in selected journals (1996-1998)

\begin{tabular}{lccc}
\hline Journal & $\begin{array}{c}\text { Total number } \\
\text { of articles }\end{array}$ & $\begin{array}{c}\text { Number from } \\
\text { RoW }\end{array}$ & $\begin{array}{c}\text { Proportion } \\
(\%)\end{array}$ \\
\hline Acta Psychiatrica Scandinavica & 473 & 75 & 15.8 \\
British Journal of Psychiatry & 637 & 42 & 6.5 \\
Psychological Medicine & 404 & 25 & 6.1 \\
American Journal of Psychiatry & 849 & 22 & 2.5 \\
Schizophrenia Bulletin & 163 & 4 & 2.4 \\
Archives of General Psychiatry & 376 & 5 & 1.3 \\
\hline
\end{tabular}

World Health Organization

$3.0 \%$

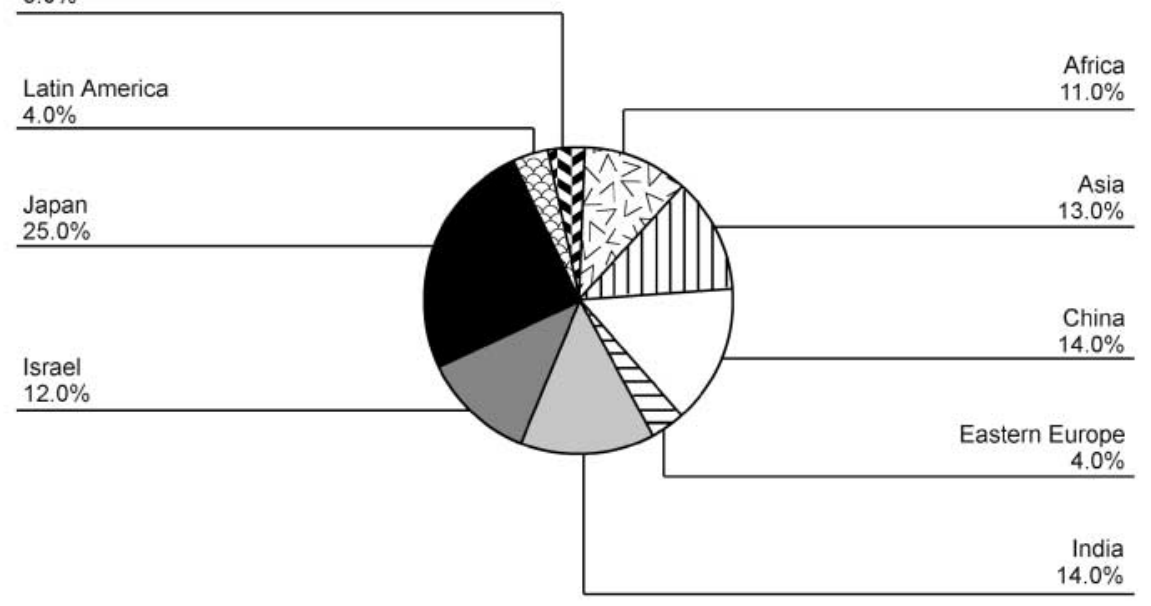

Fig. I The regional distribution of articles from the RoW, rest of the world.

Table 2 Where do different world regions publish their work?

\begin{tabular}{|c|c|c|c|}
\hline Region & $\begin{array}{c}\text { Journal I } \\
\text { (\%) }\end{array}$ & $\begin{array}{c}\text { Journal } 2 \\
\text { (\%) }\end{array}$ & $\begin{array}{c}\text { Euro-American } \\
\text { collaboration (\%) }\end{array}$ \\
\hline Eastern Europe $(n=7)$ & Acta (43) & PM (29) & 4 (57) \\
\hline India $(n=24)$ & Acta (54) & $B J P(2 I)$ & 7 (32) \\
\hline China $(n=24)^{\prime}$ & $B J P(42)$ & Acta (29) & 8 (33) \\
\hline Asia $(n=10)$ & Acta $(60)$ & $B J P(30)$ & $6(60)$ \\
\hline Sub-Saharan Africa $(n=19)$ & PM (32) & Acta (26) & $10 \quad(53)$ \\
\hline Latin America $(n=7)$ & $B J P(43)$ & $\operatorname{Arch}(29)$ & $3(43)$ \\
\hline Middle East/North Africa $(n=13)$ & Acta (54) & $B J P(3 I)$ & I (8) \\
\hline Japan $(n=43)$ & Acta (70) & $B J P(12)$ & $2 \quad(5)$ \\
\hline Israel $(n=20)$ & $B J P(35)$ & $A J P(25)$ & $3(15)$ \\
\hline Multinational $(n=6)$ & $P M(100)$ & - & $6(100)$ \\
\hline Total $(n=173)$ & Acta (43) & $B J P(24)$ & $50 \quad(30)$ \\
\hline
\end{tabular}

Acta, Acta Psychiatrica Scandinavica; BJP, British Journal of Psychiatry; PM, Psychological Medicine; Arch, Archives of General Psychiatry; AJP, American Journal of Psychiatry.

I. The figures for China include Taiwan (9/24 articles), Hong Kong (10/24 articles) and mainland China (5/24 articles).

Figures in parentheses are the percentage of articles from that particular region in the specific journal.

the proportion of papers from each region which involved authorship from EuroAmerican countries.

Of the 173 articles, the vast majority were cross-sectional surveys of various mental disorders and clinical descriptions of various psychiatric disorders. Only 11 articles $(0.003 \%$ of the total number of articles published) described trials or intervention research in the RoW.
Of the six journals approached, two (Schizophrenia Bulletin and American Journal of Psychiatry) were unable to furnish any data because they did not keep records on the country of origin of submitted papers. One journal (Archives of General Psychiatry) was unable to share the information because "it would violate confidentiality". Data provided by Psychological Medicine showed that just over $10 \%$ of the 969 papers submitted to the journal between 1996 and 1998 were from the RoW; $24 \%$ of papers submitted from the RoW were accepted for publication, whereas the rate was $37 \%$ from Western Europe and North America $(P<0.01)$. Statistics for Acta Psychiatrica Scandinavica were only available for the year 1998. During this year, 133 of the 514 submissions were from the RoW (26\%). The acceptance rate of papers from the RoW was less than half of that for Euro-American papers (13\% v. 30\%; $P=0.08$ ). Similarly, for the British Journal of Psychiatry, just $13 \%$ of 2299 papers submitted during the 3-year period were from first authors based in the RoW. The acceptance rate for these papers was significantly lower $(13 \% v$. $29 \% ; P<0.001)$.

\section{DISCUSSION}

\section{Low proportion of international representation}

This survey of six leading international psychiatric journals shows that over $90 \%$ of all the literature published is derived from Euro-American societies. Thus, none of the six leading journals can be considered to reflect the international perspective of psychiatric research. However, considerable variations are seen between journals. Thus, $16 \%$ of articles in Acta Psychiatrica Scandinavica were from the RoW, compared to just $1 \%$ of those in Archives of General Psychiatry. Indeed, the three European journals were far ahead of the three American journals in their international representation and over $80 \%$ of all the papers from the RoW published in 1996-1998 appeared in Acta Psychiatrica Scandinavica, British Journal of Psychiatry and Psychological Medicine. It is fair to conclude, then, that these three journals should be the preferred journals for mental health professionals in Asia, Africa, Latin America and Eastern Europe.

Of papers from the RoW, the bulk of research published is from Japan, Israel, 
India and China. Between them, these four countries are responsible for nearly twothirds of the literature from outside North America and Western Europe. Latin America and Eastern Europe have very low rates of contribution. There are several potential reasons for this finding. Japan and Israel have strong academic traditions and economies. India and China are the most populous nations in the world and have one of the largest mental health professional bases in the RoW. The strengths of these four countries are also reflected in the findings that a relatively low proportion of articles are the result of collaborations with Euro-American countries. Journal preferences were also apparent. Thus, articles from Japan were the most common for the American Journal of Psychiatry and Acta Psychiatrica, from China (including Hong Kong and Taiwan) for the British Journal of Psychiatry and from sub-Saharan Africa for Psychological Medicine. Latin American representation may be low because much of the literature appears in Spanish- and Portuguese-language journals published within Latin America. Indeed, this may be the case for the bulk of research from the RoW, which tends to be published in journals "which are not always easily accessible" (Sartorius, 1998).

\section{Reasons for low international representation}

It is apparent that despite efforts to establish psychiatry as a truly international medical discipline, the overwhelming majority of articles in major psychiatric journals originate from a few countries which share Western European and American cultural and health systems. We can only speculate on the reasons behind the low international representation in high-impact psychiatric journals. One possible reason which we attempted to investigate was that the proportion of submissions was low. Information sent by three European journals confirmed that just over $10 \%$ of all submissions were from the RoW. The low submission rate is cause for worry since it reflects the limited capacity for psychiatric research in most countries of the world, which, in turn, potentially restricts the growth of the subject as an international discipline. The low submission rates may be attributed to a number of factors. Perhaps the single most important is the great shortage of trained researchers and funds for psychiatric research in many developing countries. Opportunities for training and supervision in research are very limited (Okasha \& Karam, 1998; Sartorius, 1998). It is estimated that only $5 \%$ of global health research funds are devoted to problems in developing countries, even though these account for over $90 \%$ of the "world's potential life years lost" (Mari et al, 1997). This imbalance is likely to be even greater for mental health research, given its low priority in developing countries. The low submission rates also suggest that the programmes to raise mental health research capacity in developing countries, suggested as a major outcome of the World Health Organization (WHO) programmes in promoting international mental health (Eisenberg et al, 1999), have not had the level of impact that might have been desired.

Next, we should consider factors related to the way articles are reviewed for journals. Ultimately, the key criterion for publication is the perceived importance of the work and rigour of the scientific methods employed. Studies which simply replicate established knowledge without any discussion of cultural linkage may not merit publication. Data from the journals points to an acceptance bias against papers from the RoW. Acceptance bias may also partly explain the finding that the commonest origin for RoW articles in American journals comes from nations with close political and academic ties with the USA.

Reviewers and editors may judge papers from the RoW as being less relevant to local readership and reject papers on this ground. Thus, any journal is likely to pay attention to the needs of its readership, and the vast majority of subscribers to the journals included in this study are from developed countries. It may be an assumption that these readers are less interested in articles from developing countries. There is a tendency for journals to publish papers from the RoW if their findings show something unusual or unique to that setting, as if their scientific value to the subject of psychiatry is somehow less important. On the other hand, work from Western societies is automatically deemed to be of international significance. One way of analysing this hypothesis would be a comparative content analysis of reviewer comments on Western and RoW articles.

Other factors may include low quality of submitted papers, including poor research design and methodology, language difficulties for authors from countries where English is not the academic language, and the growing emphasis on biological research in major journals, which is not only of less relevance to mental health in developing countries but is also limited in its appeal owing to restricted availability of research infrastructure.

\section{Implications of low international representation}

If the nature and aetiology of diseases can often be best understood by examining the epidemiological characteristics of diseases in different environments, and innovative treatments discovered by throwing a wide net over practices within a wider global context, then the present state of the origin of psychiatric literature is limiting the growth of the subject itself. From a regional perspective, however, the damage is even greater. Psychiatry as a biomedical discipline had its roots in Europe and is a relatively young discipline in most countries. Its history in many countries is tainted by its association with colonial-era asylums and terrible abuses of human rights. Many of these abuses are evident even in recent years, for example, in the large mental hospitals in India (National Human Rights Commission, 1999). To remove stigma from psychiatry will need greater space for research from these countries on international platforms in order to demonstrate that original and innovative, locally generated programmes on mental health care are feasible and successful.

The tiny proportion of research which describes interventions or treatments for mental disorders is a major source of concern. It is essential to generate treatment research from a variety of regions in the world because efficacy is likely to vary according to health systems, cultural and pharmacodynamic factors (Mari et al, 1997; Patel, 2000b). Ultimately, though, treatment and policy-oriented research will provide the crucial evidence needed to follow up the much-replicated findings regularly thrown up by surveys of enormous numbers of persons suffering from mental disorders. Health policy-makers and planners in developing countries are unlikely to be impressed solely by data from the West; the lack of intervention research is further confirmation that the 'so what?' question in response to the huge prevalence figures still cannot be confidently answered. 


\section{Correcting the imbalance}

Three sets of strategies may be identified as potential methods of increasing international representation in the psychiatric literature. First, and perhaps the most important step, is the need to raise skills and capacity for research in diverse regions of the world. This could be achieved in a number of ways, including establishing research-oriented training programmes linked with ongoing project collaborations, facilitating research training in the form of short courses and distance education, and providing a resource for advising on research design, methodology and analysis. Multilateral agencies such as the WHO and international research institutions can play an especially influential role in this process. In this regard, it is worth noting that there is considerable variation between and within developing countries in research capacity and output (Sartorius, 1998). Established research institutions in developing countries should be encouraged to play a leading role in raising capacity for mental health research skills.

The second set of strategies involve providing greater space in mainstream journals for articles from the RoW. We do not suggest that there should be any form of 'affirmative' action in decisions regarding acceptance of papers from the RoW, because it would be at best patronising and at worst discriminatory. However, it may be possible to consider editorial styles which are collaborative, so that important papers are not rejected for purely style or language reasons. Transparency on the relative acceptance rates from different regions of the world may illuminate any weaknesses or biases which operate in journals. Refereeing panels for papers from the RoW should have a significant presence of reviewers who are sensitive to the health systems of these countries. We would argue that respected academics from the RoW should also be asked to review work from Western societies.

Finally, we acknowledge that journals are entitled to publish material which they wish to emphasise, for example, biological research, or research which is of interest to their primary readership. This is especially true of three journals we reviewed which are primarily the journals of national or regional psychiatric organisations. Health-services-oriented literature from, say, Brazil or Indonesia, may not be considered relevant or interesting to the

\section{CLINICAL IMPLICATIONS}

- Only a small fraction of the total psychiatric literature in six leading journals originates from countries outside North America, Western Europe and Australia/ New Zealand; this suggests a low research capacity in the international context.

- Most research from other countries is clinical or survey-based; the next generation of studies needs to focus on interventions.

- The low international representation of psychiatric literature is potentially limiting the growth of the subject as a relevant public health discipline in developing countries.

\section{LIMITATIONS}

- The survey only focused on psychiatric journals; thus, no comparison can be made with journals from other medical specialities.

- Journals originating in other regions, such as India and Latin America, were not included in the review because they were not high impact.

- No information was obtained on the reasons for rejection of papers from different regions to investigate the acceptance bias against papers from the rest of the world.

VIKRAM PATEL, MRCPsych, ATHULA SUMATHIPALA, MRCPsych, Institute of Psychiatry, London

Correspondence: Dr Vikram Patel, Sangath Centre, 84I/I Alto Porvorim, Goa 40352I, India. E-mail: vpatel@goatelecom.com

(First received 16 May 2000, final revision 26 September 2000, accepted 26 September 2000)

readership. In some research institutions in developing countries, there is a preference for publishing high-quality work only in high-impact journals. As a result, indigenous journals remain the last choice and, unsurprisingly, remain low in their impact factor. Thus, there is a potential for a third strategy: a high-quality new journal with a specific orientation to world mental health. Such a journal would need to be multi-disciplinary and would provide a forum not only for research, but also for innovative programme and service developments, which might contribute just as much (if not more) to the growth of psychiatry as a relevant international public health discipline.

\section{ACKNOWLEDGEMENTS}

We acknowledge the help of the editorial offices of the British Journal of Psychiatry, Acta Psychiatrica Scandinavica and Psychological Medicine in sharing some of the data presented in this article. We are also grateful to Anthony Mann, Martin Prince, Povl
Munk-Jørgensen and Eugene Paykel for their comments on a draft of this article.

\section{REFERENCES}

Eisenberg, L., Goldberg, D., de Girolamo, G., et al (1999) Promoting Mental Health Internationally. London: Gaskell.

Mari, J., Lozano, J. M. \& Duley, L. (1997) Erasing the global divide in health research. British Medical Journal, 314, 390

Murray, C. \& Lopez, A. (1996) The Global Burden of Disease. Boston: Harvard School of Public Health.

National Human Rights Commission (1999) Quality Assurance in Mental Health. New Delhi: NHRC.

Okasha, A. \& Karam, E. (1998) Mental health services and research in the Arab world. Acta Psychiatrica Scandinavica, 98, 406-4/3.

Patel, V. (2000a) Health systems research: a pragmatic model for meeting mental health needs in low-income countries. In Unmet Need in Psychiatry (eds G. Andrews \& S. Henderson), pp. 353-377. Cambridge: Cambridge University Press.

- (2000) Why we need treatment evidence for common mental disorders in developing countries. Psychological Medicine, 30, 743-746.

Sartorius, N. (1998) Scientific work in Third World countries. Acta Psychiatrica Scandinavica, 98, 345-347. 